\title{
Children's Attitudinal Dimensions of Living Things: Some Implications for Environmental Education
}

\author{
T. Geetha \\ Associate Professor, Department of Education, University of Delhi, Delhi, India
}

\begin{abstract}
The Environmental Education may be considered to be an approach to education which incorporates considerations of environment rather than being a separate part of education. In other words environmental approach aims to evolve an environmental ethics i.e. a balanced way of thinking, feeling and acting towards the environment. A well articulated international initiative emerged in Tibilisi Conference, 1977 put forth a set of objectives of EE to take care of awareness, knowledge, attitude, skills and participation. This study explored the children's attitude towards living things in their immediate environment or those concerned them. With appropriate theoretical and empirical analysis, it is concluded that the egalitarian view of the children where all creatures were equal and have similar rights in the world was strong. Many children were found demonstrating humanistic, moralistic, naturalistic and aesthetic attitudes towards living things.
\end{abstract}

Key words: environment education, attitude development, attitude scale, egalitarian and humanistic views.

\section{Introduction}

The real value of the biodiversity present on the earth and more so of our country is to be understood that we can take proactive role in conservation and protection of the biodiversity which we have inherited and for which we are the present custodians. Complex web of interrelated factors exist that directly or indirectly influence an individual's commitment to pro environmental action and wise stewardship in the preservation of species diversity. Although personality factors play a role in this commitment, knowledge and attitude appear to be very strong components (Hungerford, Hines, and Tomera, 1986/1987; Hungerford and Volk, 1990; Volk and McBeth, 1998; Hwang, Kim, and Jeng, 2000; Kollmuss and Agyeman, 2002)

Silberstien, M., and Tamir, P., 1981, 'Factors which affect student's attitudes towards the use of living animals in learning biology' found that students can make a clear distinction between the use of animals in research as opposed to the use of animals in instruction. The results showed that : (a) the degree of usefulness or damage to man associated with the animal; and, (b) the taxonomic position of the animal affects students in their differential attitude toward the use of animals. Perhaps students considered the mutual relationship between man and animal in terms of trade-off - those which give and contribute to man should be rewarded and those which cause damage should be punished. Alternatively, perhaps emotional feelings such as empathy versus feeling of disgust, or liking versus dislike, played a prominent role in shaping the attitudes.

Millett, K., and Lock, R., 1992, 'GCSE Students' attitudes towards animal use: some implications for biology/science teachers' set out to investigate what the students in their $10^{\text {th }}$ year of school knew and felt about some ways in which animals are used in their study. Most students were against the use of animals to research cosmetic or household products. 83 percent females and 61 per cent males felt that it was wrong to breed animals purely for dissections. Keeping animals for their food products and their use in farming was considered acceptable by many and their use for testing household products and cosmetic products was not favoured.

Stanisstreet, M., Spafforth, N., and Williams 1993 on 'Attitudes of children to the uses of animals' found that approximately three-quarters of the secondary school pupils surveyed objected to the use of animals for clothing, and over one-third disapproved of confinement of animals for human recreation in zoos. Although some two-thirds of pupil did not object to the use of animals for food, few thought that intensive rearing methods were justified. Surprisingly, only about half of the pupils indicated a positive attitude to the conservation of animals. In general older pupils gave less 'sympathetic' responses to some statements than did younger ones. Similarly, male pupils gave less 'sympathetic' responses than females.

A follow up study by Lock, R., 1995, 'GCSE students' attitudes to dissection and using animals in research and product testing' done on 469 students aged 14-15 years in 10 high students in England revealed there was much ambivalence in attitudes to using animals in research and product testing. There was a high level of support for peers who object to dissection. Objectors to dissection were, however, likely to be met with derogatory comments particularly if they were male.

Dreyfus, A., 1995, 'Biological knowledge as a prerequisite for the development of values and attitudes'. The paper discussed the relationship between secondary school biological knowledge and sociohuman values. It was shown that, on science- and technology-related issues, sound attitudes cannot be developed without some basic scientific knowledge and insights. The discussion about various issues such as 
herbivores, ferocious carnivore, wild life conservation, extinction, biodiversity, uses of various pesticides' has shown that it is only when armed with some essential knowledge, that people may be able to adopt a relevant set of values, which, in turn, will guide them in the development of carefully balanced and 'reasonable' attitudes.

Phillips, C.J.C., and McCulloch, S., 2005, 'Students attitudes on animal sentience and use of animals in society', conducted a cross cultural study to investigate the beliefs of 425 students of different nationalities on animal sentience and attitude towards the use of animals. European students and, to some extent, those from the USA were less likely to condone cruelty to animals on farms than students from Asian countries. Students from Europe had more concern for suffering during life than the students from Asia, but there was no difference in the extent of reverence for animal life. The order of sentience across nationalities that was attributed to different species was monkey $>\operatorname{dog}>$ newborn baby $>$ fox $>$ pig $>$ chicken $>$ rat $>$ fish. Correlations between animal sentience and attitudes toward the uses of animals showed that the students opposing, advocating constraints on, the use of animals in the society attributed more sentience to those animals.

Barney, E.C., Mintzes, J.J., and, Yen Chiung-Fen, 2005 in their study 'Assessing knowledge, attitudes, and behaviour toward charismatic megafauna; the case of dolphins' explored conceptual understanding, attitudes, and behaviours of 289 American elementary, secondary, and college age students. Results suggested that the important megafaunal species, dolphins was poorly understood by the public at large. The most knowledgeable and environmentally responsible participants were found much less likely to engage in disruptive or potentially harmful harassment behaviour. Most important, they suggested that significant harassment behaviour is related in complex ways to knowledge and attitudes.

To conservation and environmental educators, affective and behavioural outcomes are often considered as important as cognitive goals (Leeming, Dwyer, and Bracken, 1995). Typically formal and informal environmental education programs seeks to encourage attitude and behaviours that are "environmentally responsible", with a view towards conserving natural resources and preserving and protecting the diversity of life forms in a variety of habitats, especially among those species considered endangered or threatened by human activity.

The International Union for Conservation of Nature and Natural Resources' (IUCNR), 1970, first brought out the need for development of skills and attitude brought about by the clarification of concepts and recognition of values as necessary to understand and appreciate the interrelatedness among man, his culture and his biophysical surroundings. Self formulation of a code of behaviour and practice in decision making about issues concerning environmental quality were considered as integral to environmental education.

The comprehensive set of objectives of Environmental Education prepared at the 'International Environmental Education Programme' (IEEP), founded by UNESCO/UNEP, launched in 1975 at Belgrade also focussed on this aspect by stating that every person must be provided with opportunities to acquire the knowledge, values, attitudes, commitment, and skills needed to protect and improve the environment.

The outcomes of Tibilisi Conference of 1977, whose final reports sets out various objectives of Environmental Education also reflected the role of knowledge and attitude for the protection and conservation of environment. It was stressed that 'knowledge' helps children gain a variety of experience, in and acquire a basic understanding of the environment and its associated problems and 'attitude' help them acquire a set of values and feelings of concern for the environment and motivation for directly participating in its improvement and protection.

Two of the three interlinked components 'education about the environment' and 'education for the environment' that must form the basis of any environmental education programme as reflected by Tibilsi Conference of 1977 has the purpose of developing knowledge and understanding about the environment and are concerned with values, attitudes and positive action for the environment.

In India also the objectives of environmental education are based on these international considerations and one of the main objectives is to help students develop sensitivity and attitudes that favour concern for a healthy environment and the preservation and conservation of biodiversity and ecosystems. This is also reflected in the textbooks at all levels of the schooling through topics aiming to spread conceptual knowledge about the concept of life and various life forms and bringing out the issue of their interaction with environment and with human beings.

Kellert's (1996) identified various attitudinal dimensions that people demonstrate towards living things particularly wildlife, and the environment. 
Kellert's attitudinal dimensions toward wildlife and the environment, 1996

\begin{tabular}{||l|l||}
\hline \hline AESTHETIC & INTEREST IN THE ARTISTIC AND SYMBOLIC CHARACTERISTICS OF ANIMALS. \\
\hline Dominionistic & interest in the mastery and control of the animals, as in sporting or other competitive contexts. \\
\hline Ecologistic & concern for the environment as a system and for interrelationships of wildlife species and the environment. \\
\hline Humanistic & interest and strong affection for animals, with strong emotional attachment and "love" for them. \\
\hline Moralistic & $\begin{array}{l}\text { concern for the right and wrong treatment of animals, with strong opposition to exploitation or cruelity towards } \\
\text { animals. }\end{array}$ \\
\hline Naturalistic & interest in direct experience with animals and exploration of nature \\
\hline Negativistic & orientation toward an active avoidance of animals as a result of dislike or fear \\
\hline Neutralistic & orientation towards a passive avoidance of animals as a result of indifference \\
\hline Scientific & interest in physical attributes and biological functioning of the animal \\
\hline Utilitarian & concern for the practical and material value of animals; their body parts or habitats, or both. \\
\hline
\end{tabular}

These dimensions however may be applied to investigate the attitude of people towards any form of life, depending on the purpose of the study.

The student's attitudes towards living things will become adult attitudes unless they have the experience of exploring the issues further and coming to understand their own, and other's points of view. In this light the present study was conducted with the aim of analyzing the children's attitude towards living things. The study has posed a major research question as follows:

What is our understanding of children" attitude towards living things in their immediate environment or those concerned to them?

\section{Design of the Study}

Investigation and exploration of attitudes of children towards living things was carried out with the help of a questionnaire presented in three forms:

\section{(i) Attitude scale}

In the first form, 15 statements were listed concerning the issue of attitude towards living things. Students were asked to tick the appropriate column: agree; disagree; or don't know. The problems were constructed on the basis of seven dimension of the many proposed by 'Kellert's attitudinal scale towards wildlife and the environment' (1996): utilitarian (6); moralistic (3); humanistic (2); aesthetic (1); naturalistic (1); dominionistic (1); and negativistic (1). These were modified according to the present study by including all living things instead of animals only. To reduce bias, statements were constructed so that agreement with some statements indicated possible negative attitude, whereas agreement with other statements indicated possible positive attitudes. The statements were in random order but were grouped according to the respective dimensions (table 1) for the purpose of analysis and interpretation.

\section{(ii) Open ended questions}

The second set of questions included were open ended questions. An issue was presented in each of the question and children were asked to present their view with suitable reasons and arguments. These helped in the interpretation of the responses. Keeping in view the descriptive nature of the study, children's responses were established by presenting them in their own words.

\section{(iii) A multiple choice question}

Here options were provided to the children to investigate the magnitude of discussions of the concerned issue with other members of the society as in class, family, friends and others; and students were to choose any number of options and provide options if they choose the 'other' option.

In the backdrop of the purpose of this study and the research question a blend of both qualitative and simple statistical techniques were adopted.

For the present study, 120 children of age group 10-11 years enrolled ingrade 6 according to the CBSE curriculum were purposively and randomly selected from two public schools in Delhi (according to the convenience of the researcher).

\section{Analysis and Findings}

The analysis was done in two parts and the understanding of the attitudinal dimensions of children towards living things was aimed at by consolidation. 


\subsection{Attitude development: Quantitative analysis}

TABLE 1: Distribution (\%) of children's responses

\begin{tabular}{|c|c|c|c|c|}
\hline $\begin{array}{l}\text { S. } \\
\text { NO. }\end{array}$ & STATEMENT & AGREE & DISAGREE & $\begin{array}{l}\text { DON'T } \\
\text { KNOW }\end{array}$ \\
\hline \multicolumn{5}{|c|}{ Humanistic dimension } \\
\hline & Animals/plants should be preserved for their own sake & 51 & 28 & 20 \\
\hline & I take care of plants in my house. & 93 & 5 & 0 \\
\hline \multicolumn{5}{|c|}{ Moralistic dimension } \\
\hline & Plants, animals \& humans are equally special & 87 & 8 & 5 \\
\hline & Animals deserve legal rights. & 68 & 20 & 7 \\
\hline & $\begin{array}{l}\text { Keeping animals in captivity is cruel even if they are treated } \\
\text { nicely. }\end{array}$ & 46 & 43 & 6 \\
\hline \multicolumn{5}{|c|}{ Utilitarian dimension } \\
\hline & $\begin{array}{l}\text { Plants \& animals should be saved for the benefits of future } \\
\text { generations }\end{array}$ & 82 & 14 & 3 \\
\hline & $\begin{array}{l}\text { Deodorants, cosmetics products \& household cleaning products } \\
\text { should be tested on animals to make sure they are safe for humans } \\
\text { to use (even when they may cause harm to them) }\end{array}$ & 10 & 82 & 8 \\
\hline & $\begin{array}{l}\text { Animals should be used for dissections to teach biology lessons in } \\
\text { schools. }\end{array}$ & 13 & 81 & 6 \\
\hline & A tree coming in the way of a road should be cut. & 25 & 65 & 13 \\
\hline & $\begin{array}{l}\text { Animal's skin should be used to make leather products (shoes, } \\
\text { purse, belts, etc.) which are useful for humans. }\end{array}$ & 23 & 74 & 3 \\
\hline & Farmers should keep sheep for their wool and not for meat. & 79 & 17 & 4 \\
\hline \multicolumn{5}{|c|}{ Negativistic dimension } \\
\hline & I would stay away from a stray dog because they are scary. & 55 & 35 & 6 \\
\hline \multicolumn{5}{|c|}{ Aesthetic dimension } \\
\hline & Animals should be valued because they are beautiful creatures. & 69 & 21 & 5 \\
\hline \multicolumn{5}{|c|}{ Naturalistic dimension } \\
\hline & I would rather see the lion in captivity than in wild. & 24 & 54 & 18 \\
\hline \multicolumn{5}{|c|}{ Dominionistic dimension } \\
\hline & $\begin{array}{l}\text { I believe a person sometimes has to punish animals to get the work } \\
\text { done. }\end{array}$ & 23 & 66 & 11 \\
\hline
\end{tabular}

'Moralistic' dimension investigated the children's concern for the right and wrong treatment of living things, with strong opposition to exploitation or cruelty towards animals'. It was found that in the moralistic dimension students were more likely to agree with the statements 1 which condoned the importance of all living things as equal and therefore the need for their survival . $69 \%$ gave them an equal status to humans by asserting that animals are equally deserving of legal rights. This brings out the humane concern of these children towards the increasing number of endemic species in our country and in the world. The children had mixed views about keeping the animals in captivity even if they are treated nicely and an almost equal number agreed and disagreed at the same time.

93\% children showed concern for plants by taking care of those present in their homes or gardens demonstrating positive 'humanistic' attitudes i.e. 'interest and strong affection for living things, with strong emotional attachment and "love" for them'. Almost half of the children studied, felt that living things should be preserved for their own right whereas, $28 \%$ felt the opposite and disagreed, bringing out the supremacy of humans over other creatures.

Positive 'aesthetic' attitude i.e. interest in the artistic and symbolic characteristics of living things, was found when a swooping $69 \%$ felt that animals are beautiful and contribute to the nature's bounty.

Children also had 'negativistic' attitude: 'orientation toward an active avoidance of living things as a result of dislike or fear', toward some life forms. 55\% would like to stay away from street dogs as they seemed to be scary of them, but $35 \%$ had no such problem.

When it came to the point of observing animals for whatever purpose it may be, more numbers (54\%) preferred naturalistic settings than in cages bringing out the positive 'naturalistic' attitude i.e. 'interest in direct experience with living things and exploration of nature'. Some (24\%) preferred the latter option, and a few could not decide.

Taking a look at the 'utilitarian' dimension that investigated the children's 'concern for the practical and material value of living things; their body parts or habitats, or both, it was evident from the results that children had mixed views about utilization of living objects for various purposes. A high number (82\%) felt the need to save them for the benefits of future generations. A similar number disagreed on two other aspects of utilization of animals for product testing and teaching purposes, bringing out the sensitivity of children. $74 \%$ believed that animals' skin should not used be used for making leather products and it is cruel to do so. On the other hand around one fifth of them agreed on the same issue and saw no harm in using leather products. When 
it came to the use of sheep for the wool, children agreed to it as removal of wool from sheep's body does not cause any harm to it. When a tree is coming in the way of road it must be cut as it will create obstacles in the smooth traffic flow. This was felt by $25 \%$ of the children whereas $65 \%$ of their friends say this act demonstrates insensitivity to them.

An almost equal number (23\%) felt that if an animal is causing us some trouble just like the tree was doing on the road, they must be punished whereas $66 \%$ disagreed with their counterparts, condemning the 'dominionistic' attitude i.e. 'interest in the mastery and control of the living things, as in sporting or other competitive contexts'.

\subsection{Attitude development: Qualitative analysis}

A set of open-ended questions revealed their frame of reference and the reasons for their responses. These responses were classified loosely by the researcher and highlighted ones are presented under each response focused for different questions. The inference was drawn in order to interpret meaning and significance of the responses.

\section{Do plants also feel pain like animals if we hit them with a rod/or pierce it with a pin? Give reasons for your answers. \\ Children were more likely to agree $(76 \%)$ that plants also feel pain if we hit them with a rod or pierce it} with a pin. Plants are living beings just like humans, and since humans feel pain if physical harm is caused to them, plants also must be feeling the same was the most common justification. Though children agree that plants are living things, most of the reasons for the painful feelings of the plants were not based on biological attributes. Very few could recognize that plants are affected by various stimuli. A varied number of reasons for the attribution of feelings to plants come up as: presence of soul, presence of skin, presence of organs, etc. Many students tried to justify their response by explaining the functions of plans such as photosynthesis, reproduction, etc. which have no relation of the plant' response to stimuli as hitting or piercing. Some of the common arguments presented by children are stated as follows in their own words.

Yes, plants feel pain because:

"They are also living things"

"All living things feel pain"

"Plants also feel pain, but they cannot tell us as they cannot speak"

"All living things respond to stimuli"

"They also get hurt but cannot respond to stimuli of being hurt or being happy"

"They also have cells and so they could also feel"

"They also have skin like us and can sense pain"

"They also have organs in their body and if we slice them into two, they get pain"

"They also have a soul"

"They are living creatures of our country. If we hit them, the numbers will get reduced"

"They also breathe and make food by the process of photosynthesis"

"Just because they don't have eyes, ears and can't move they don't become non-living things. They also feel and we should respect them"

"Plants have been proved to be living and a reason for that is that they respond to stimuli like the touch-me-not plant shrinks if you touch them"

Nearly one fifth $(21 \%)$ of the sample believed that plants do not feel pain and only $3 \%$ could not decide on their stand. The arguments provided for the negative response were also not based on any biological attributes but the belief that they were once part of a living thing and now they are dead or a part of non-living thing. Some other arguments that come up are presented here.

No, plants don't feel pain because:

"They are living things but they are also a part of non-living things"

"They were once living creatures of the earth, but now they are dead"

"They are very strong"

"They are made up of wood"

"They do not react"

"They do not have brains"

"They do not move away"

"They do not harm us if we harm them"

"They are created by God"

"They do not have skin"

"We cannot see them getting pain" 
It could be inferred here that since majority of the children recognize plants as sensing and feeling beings, on whatever grounds, they will be more considerate towards their protection and conservation rather than those who did not and hold humanistic as well as moralistic attitudes. Those who could not recognize plants as living will not be able to show positive attitudes towards them

TABLE 2 Germs and insects are also living beings. Is it alright to kill them? Give reasons for your answers.

\begin{tabular}{||l|l|l||}
\hline \multicolumn{1}{|c|}{ S.No. } & \multicolumn{1}{|c||}{ Response Focus } & \multicolumn{1}{|c|}{ Response Weightage of Children } \\
\hline 1 & YES, there is no harm in killing germs and insects & $27 \%$ \\
\hline 2 & NO, germs and insects should not be killed & $43 \%$ \\
\hline 3 & Partly agree, partly disagree & $15 \%$ \\
\hline 4 & I don't know & $15 \%$ \\
\hline
\end{tabular}

Germs and insects being small in size and therefore unavailable for observation of their biological attributes are often mistaken as non-living (Osborne and Freyberg, 1985). However, most of the children in this study contradicted with this finding and $43 \%$ believed that these are also living organisms and therefore should not be killed. Again here also the backdrop against many disagreements was moralistic than biological. Their importance for maintaining balance in nature was established by many demonstrating the ecologistic attitude. This and few other reasons that accompanied were:

No, we should not kill germs and insects because:

"They should not be killed using harmful chemicals"

"They should not be studied by killing them, rather by observing carefully"

"They also feel pain"

"They also have fathers, mothers, and sisters like us"

"We should not kill them as earth will loose its fertility and balance in nature'

"Some of them are useful for us"

"We should capture them and set them free in some other area"

"Because they help in seed germination and dispersal"

"They help in decomposition of dead plants and animals"

"God has made them and we have no right to kill them"

"They are also sacred of death like us"

"If there are mosquitoes in our home, we can keep a lizard who will eat them, this way lizard is helpful for us and keeps the natural balance"

"Some of them like spiders are used to make medicines and are helpful for us"

"It is not their fault if they are small and we look like giants to them. They survive only on eating the stuff lying on the floor. They bite us because they are scared of us and think that we will harm them"

$27 \%$ children maintain the negativistic attitude that since germs and insects are harmful creatures and are the cause of many deadly diseases like dengue and malaria, they must be destroyed. Few of them also blame these tiny creatures for the destruction of food and crops in the farms. Some of the responses in this regard were: "They spread diseases"

"Yes, because my mother got ill because of dengue, after which she became weak"

"They destroy farm fields"

A few children $15 \%$ could not decide whether we should kill germs and insects or not and an equal number partly agreed and partly disagreed.

'If they are harmful we should kill them, if not then we should not"'

"If it is a normal fly we should let it be, if it is a fly that spreads diseases we should kill them"

"They are harmful but helps in making curd"

"Kill them if they are harmful, but not for fun"

It is explicit from the result that children often decide the attitude towards other living beings on moralistic and sometimes on ecological grounds, but this can only be possible if they are aware of their status of 'life'. Those who believe that since germs and insects are living and therefore should not be killed unless and until they become harmful for our survival seemed to possess the most relevant attitude.

There is nothing wrong in plucking leaves and flowers of plants on streets and in gardens. Agree or disagree? Give reasons.

Only one out of hundred children studied felt that plucking leaves and flowers from roadside and garden plants is not wrong for which no reason was provided. A major $90 \%$ felt this should not be done as they are the one's causing all the beauty of the nature (aesthetic) and maintain natural balance by absorbing carbon dioxide and releasing oxygen (ecologistic), as they are a part of plants. Their importance for the plants survival itself was also recognized by many 
"They are also living beings"

"They also feel pain"

"Its similar to somebody pulling our hair"

"They give us greenery"

"They make the world beautiful"

"Plucking leaves and flowers will create shortage of oxygen andit will lead to increase in carbon dioxide"

"They are living when on the plant, when we pluck them they die"

"Plants will die if we do this"

"Because plants prepare food with the help of leaves and flowers"“They are our friends, gives us oxygen, fragrance and beauty"

"They also have full right to live"

"It might stop the growth of plant"

"Because flowers are the seats for sexual reproduction and leaves are food factory"

"They prevent soil erosion and invite rain"

Only $9 \%$ of all the children could not take a decision on this note. The chunk believing in the protection and conservation of plants showed the needed attitude of the present time. The basis of this belief being biological in nature proves that knowledge does play a role in developing 'relevant' attitudes.

\section{Have you ever taken any deliberate action to protect the animals or plants or human being? Please mention}

Less than half children (34\%), accepted that they have never taken any deliberate action to protect any living being, the reason being lack of help and their young age

"No one helped me"

"I can't stop people from harming plants, they are big and I'm small"

"No, because of nothing of this sort happens in our colony"

However $58 \%$ has done the great job in some form or the other, bringing out the increasing concerns and attitude formulation for prevention and conservation of living things around them including themselves. Some of the deeds done by these children are mentioned below.

"I saved my mother when she forgot to switch off the gas"

"By saying to my friends not to step on insects"

I saved a tree from being cut, and a dog from dg catchers"

"I don't burn crackers as they kill plans and insects"

"I took a dog who was had a broken leg to a doctor, get him cured and kept him as a pet"

"some children were throwing stones on a dog' I stopped them"

"I made a drowning plant live again by giving water and support it with a stick"

"I shouted at my servant for slapping our pet dog"

"I planted two seeds in my garden when I was young, now they are beautiful plants"

"I had participated in an activity of planting plants"

"Yes, because I love animals"

"Once an animal was feeling cold, I put blanket on him and gave food"

"My friend was trying to burn the leaves of a tree, I stopped him"

"I save my friend from a group of dogs running after him by throwing my bat on them"

Few children (8\%) who gathered some information about the uses of living objects in various purposes, seemingly cruel to them, from the questionnaire used in this study, decided that even if they have not tried the act till now they would like to do it in the future.

"No, but I'm thinking now to do my best for saving plants and animals from extinction.

TABLE 4 Do you discuss the issue of protection of plants and animals?

\begin{tabular}{||l|l|l||}
\hline \multicolumn{1}{|c|}{ S.No. } & \multicolumn{1}{|c||}{ Options } & \multicolumn{1}{|c|}{ Response Weightage of Children } \\
\hline 1 & In class & $49 \%$ \\
\hline 2 & With friends & $39 \%$ \\
\hline 3 & With family & $46 \%$ \\
\hline 4 & Others & $8 \%$ \\
\hline
\end{tabular}

This question of the written set tried to investigate the magnitude of concern of these children towards the protection of the living objects, or in the other words our biodiversity. The problem explored the magnitude of discussions among children and other members of the society about the concerned issue. It was found from the results that maximum number of discussions were carried out in classroom (49\%), followed by the family members (46\%), friends (39\%). $8 \%$ children accepted that they have initiated this discussions by other members 
of the society also such as with neighbours, extended family and kin group, poor people and some in the clubs. A few children maintained that they constantly watch 'discovery channel' which keeps them informed about the issue.

It may be concluded that children's oppose towards cruelty and uses of living beings on moral and emotional consideration. A central issue in the context of attitude in this study is the place of man in relation to other living beings. A 'homocentric' view puts the man at the centre, thus implying that man may use other living things to satisfy his needs with no restrictions. However, the results of this study brought up the contrasting views held by most of the children, i.e. the 'egalitarian' view and argues that all creatures are equal and have similar rights in the world. Children believed that living things should be used whenever their use brings about improved conditions, provided that undue suffering and cruelty are avoided and that precautions are taken to reduce the damage to them as much as possible.

It is explicit from the results that many children oppose the situations that are harmful and cruel towards living things, but accepted when the situation is seemingly harmless, or is meant for a greater purpose. For example the removal of the tree from road can protect many from the accidents. The tree can nevertheless be planted again. The degree of usefulness or damage to man associated with the living things often affect the attitude towards them. Perhaps children consider the mutual relationship between man and other living things in terms of trade-off - those which give and contribute to man should be rewarded and those which cause damage should be punished, as brought up by the germs and insects problem (table 1.D).

Many children were found demonstrating 'humanistic', 'moralistic', 'naturalistic', 'aesthetic' attitudes towards living things and condemned the 'dominionistic' attitude, and to some extent 'utilitarian' attitudes also many are still lagging behind and demonstrate a few 'negativistic' attitude. Still others are unsure on some 'moralistic' and 'humanistic' and sometimes on the 'utilitarian' dimensions.

The results also elaborate that most of the children believe in the importance of other living objects than themselves as necessary to maintain the ecological balance in the environment and have an 'ecologistic', sensitive and egalitarian attitude towards them. This number however is not very large and educational system needs to put in more efforts in this direction. The supremacy of humans and the ultimate purpose of self sustenance do erupt at many levels and this must be eradicated so that new relevant attitudes could be formulated necessary to preserve and conserve the rich biodiversity of the earth and maintain the balance of our environment.

The results brought into the light the role of school in the development of relevant attitudes towards the living objects. The role of parental attitudes and beliefs were also reflected by the large number engaging in the discussions of such issues. An informed peer group was also found to be a source of learning about the concerned issue.

Though not all, but many children were found aware of the concerned issue and were seemingly showing participation in the conservation and protection of living things at individual level in some form of the other. A few realized the need of action during the course of attempting this survey and extended their willingness to demonstrate proactive environmental behaviours in the coming future. Environmental educators, teachers and whole of the education must realize their duty in increasing the necessary knowledge base and development of proactive environmental behaviours in children.

\section{Implications for Environmental Education}

Analysis of the reasons or arguments stated by the children as the basis of their attitude towards living things revealed two major components under which all the reasons can be classified: Biological and Nonbiological.

\section{Biological component:}

Arguments based on presence or absence of biological attributes:

- Body organs as heart, brain, skin, etc; and

- Biological functions as photosynthesis, respiration, reproduction, etc

\section{Non-biological components}

Attitudes based on arguments other than biological attributes:

- Emotional aspects as feelings of pain, happiness, etc.

- Spiritual aspects as the creation of all living things by a supreme power

- Humanistic dimension as affection and emotional attachments towards living things

- Ecologistic dimension i.e. the importance of the living things for maintenance of ecological balance

- Aesthetic dimension as attractiveness and beauty of the living thing and its contribution to nature's beauty

- Utilitarian dimension i.e. the usefulness and worth of the living things and its products for humans 
- Moralistic dimension i.e. as concern for the right and wring treatment of living things, and opposition to exploitation and cruelty towards them

- Negativistic dimension i.e. avoidance of living things as a result of dislike or fear

- Dominionistic dimension i.e. control of animals for the purpose of completion of any task important to human beings

- Naturalistic dimension as experience of living things in the natural conditions

The interactions and discussions carried out by the children with other members of the society and in different settings act as a source of conceptual knowledge and formulation of varied attitudes observed. Four major sources have been found from this study: neighbours

Classroom discussions, Family interaction, Peer group interaction Other members of the society as

Keeping in view the various components attitude and their sources, a framework was developed which may be useful for understanding children's attitude towards living things in the environment. Careful analysis of the development of attitude in children brought out the above developed framework to understand children's attitude towards living things. It can be concluded that formation of 'attitude' takes place through interactions in the classroom, with family and peer group. Interaction with neighbours also acts as a source. Every interaction about living things entails some form of knowledge about them and also reveals the attitude of the interacting members towards the same. Children often pick up these attitudes irrespective of the reasons behind the acquired attitude by different people. This illuminates that development of attitude in children may take place directly through the above-mentioned sources, even in the absence of conceptual knowledge.

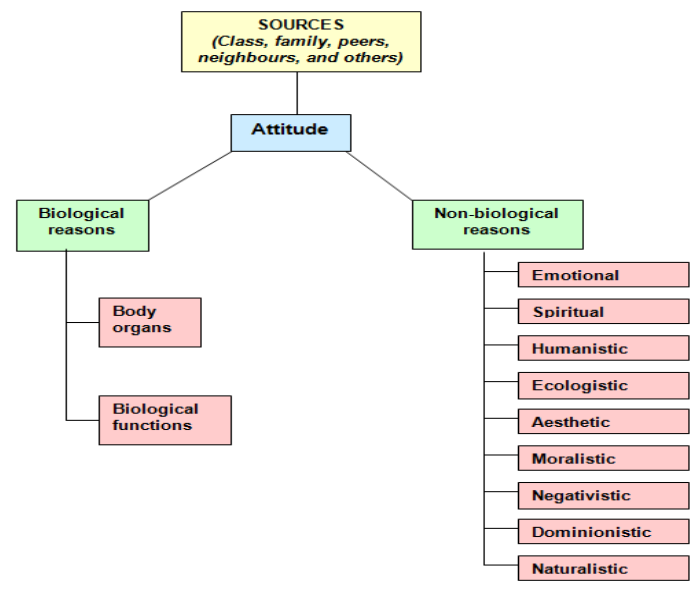

\section{Children's attitude toward living things in the environment: A framework}

Children with sound conceptual knowledge about the living things will develop attitudes based on the biological importance of the same, along with other non-biological dimensions such as emotional, aesthetic, spiritual, humanistic, moralistic, naturalistic, negativistic, dominionistic, ecologistic which are often used by children in the absence of adequate conceptual knowledge.

Teachers and environmental educators through classroom interaction must enhance the development of relevant attitude. Family and friends also play a vital role, and interactions of children with these elements of the society must be encouraged so as to cultivate a learned and environment sensitive future generation.

\section{References}

[1] Barney, E.C., Mintzes, J.J., and , Yen Chiung-Fen. Assessing Knowledge, attitudes, and behavior toward charismatic megafauna; the case of dolphins, Journal of Environmental Education, 2005, 36(2), 41-55.

[2] Best, J.W, and Kahn, J.V., Research in Education(Ninth edition), New Delhi, Prentice-Hall of India Pvt. Ltd.

[3] Brumby, M.N. Students' perception of the concept of life, Science Education, 66(4), 613-622

[4] Caravita, S., and Falchetti, E. Are bones alive? Journal of Biological Education, 2005, 39(4), 163-170

[5] Cohen,L., Manion, L., and Morrson, K. (2000). Research methods in education, London: Routledge Farmer.2000.

[6] Dolgim, Kim G., and Behrend, Douglas A. Children's Knowledge about animates and inanimate. Child Development, 1984, 55, 1646-1650.

[7] Dreyfus, A. Biological Knowledge as a prerequisite for the development of values and attitudes. Journal of Biological Education, 1995, 29(3), 215-219.

[8] Haque, M.A., Environmental Education, Environment Education, New Delhi: Institute of Advances Studies in Education, Jamia Millia Islamia.

[9] Klinberg, G. The distinction between living and not living among 7-10-year old children, with some remarks concerning the socalled animism controversy, Journal of Genetic Psychology, 1957, 90, 227-238. 
[10] Lock, R. GCSE Students' attitudes to dissection and using animals in research and product testing, School Science Review, 1995, 77 (279), 15-21

[11] Millett, K., and Lock, R. GSCE Students' attitudes towards animal use: some implications for biology/science teachers, Journal of Biological Education, 1992, 26(3), 204-208.

[12] NCERT, (2005). Environment Studies: Preamble. New Delhi: NCERT

[13] NCERT, 2005). Preamble to the science syllabus for classes VI to IX, New Delhi, NCERT.

[14] NCERT, 2005). Syllabus for Environmental Studies: class III, New Delhi, NCERT.

[15] NCERT, 2005). Syllabus for Environmental Studies: class IV, New Delhi, NCERT.

[16] NCERT, 2005). Syllabus for Environmental Studies: class V, New Delhi, NCERT.

[17] NCERT, 2005). Syllabus for Science: class VI, New Delhi, NCERT.

[18] NCERT, (2005). Chapter-9: The living organisms and their surroundings, New Delhi, NCERT.

[19] Phillips, CJC, and McCulloch, S., Students attitudes on animal sentience and use of animals in society, Journal of Biological Education, 2005, 40(1), 17-24

[20] Ravindranath, M.J., and Iyear-Reniga, U., Living traditions: India, Environment, Education and Society in the Asia-Pacific, London and NewYork: Routledge, 2000

[21] Silberstein, M., and Tamir, P. Factors which affects student's attitudes towards the use of living animals in learning biology, Science Education, 1981, 65(2), 119-130.

[22] Stanisstreet, M., Spafforth, N., and Williams, T, Attitudes of children to the uses of animals, International Journal of Science Education, 1993, 15(4), 411-425.

[23] Strommen, E. How are living things alike an different? Firstgraders' knowledge of basic life science concepts, Journal of Biological Education, 1995, 29(4), 286-292.

[24] Sykes, H., Yencken, D., Fein, J., and, Choo, F., Young people and the environment: attitudes, knowledge and behavior. Environment, Education and Society in the Asia-Pacific, London and New York: Routledge, 2000.

[25] Tamir, P., Gal-Choppin, R., and Nussinovitz, R. How do intermediate and junior high school students conceptualize living and nonliving? Journal of Research in Science Teaching, 1981, (18), 241-248. 